\title{
THE PRACTICE DEGREE OF ART EDUCATION TEACHERS IN JORDAN FOR TEACHING SKILLS IN VIEW OF KNOWLEDGE ECONOMY FROM THE POINT OF VIEW OF THEIR SUPERVISOR'S
}

\author{
Monther Sameh AL ATOUM*
}

Yarmouk University, Jordan.

\begin{abstract}
The current study intended to be acquainted with the practice degree of Art Education teachers in Jordan for teaching skills in view of knowledge economy from the point of view of their supervisors, the study sample consisted of all art education supervisors in Jordan, the descriptive research method was used in the survey, hence questionnaire was selected as a study tool which consisted of (54) paragraphs distributed on four fields, which were verified and validated. The study results revealed that the practice degree of Art Education teachers in Jordan for teaching skills in view of knowledge economy from the point of view of their supervisors (High), the four fields' standings were descending as follows: (Planning) ranked first, secondly, followed by implementation), then calendar) in third place, and finally, the (technology usage) was ranked fourth. Furthermore, the study results showed that there were no statistically significant differences related to the level of statistical significance $(a=0.05)$ among the arithmetical averages for estimating the sample on the overall paragraphs' scale practice degree of Art Education teachers in Jordan for teaching skills in view of knowledge economy from the point of view of their supervisors. Due to the variable of experience year's number, gender, and the study revealed several recommendations.
\end{abstract}

Keywords

Art Education, Teachers, Jordan, Skills, Knowledge, Economy.

\section{Introduction:}

Attention to the sustainability of the economic, social and cultural development of societies increased all over the world at the end of the twentieth century and the beginning of the twentyfirst century through education, as many international organizations were interested in education for sustainable development, and educational institutions in their turn focused on the individual being an active element in society, and that from By creating the conditions necessary to give him many values, skills and sustainable experiences to work to make him able to develop his society, solve its problems and advance it, the current challenge for educational institutions and their various programs, represented by academic subjects in general, stems from the accelerating global changes. Curricula must be developed, reviewed and developed continuously. In turn, it seeks to address the higher skills of the Global Economy and Sustainable Development Group, for a better and more advanced life by providing and providing the knowledge, skills and creative experiences required to succeed in the knowledge economy.

In this field, Jordan was not far from that interest, as the Ministry of Education developed its curricula, including all academic courses, including art education curricula, as they were built

\footnotetext{
* Corresponding author: education@yu.edu.jo
} 
in a manner consistent with development plans, in order to achieve the goals of developing education based on a knowledge economy. A set of teacher guides and textbooks in line with students' levels and the school educational environment.

The art education subject is considered one of the important materials for developing learners 'personalities through its various fields, which is to provide effective educational opportunities for students, increase their academic performance and build their various skills, especially in the basic education stages, to prepare them for the subsequent stages. The art education subject contributes to providing them with thinking skills, solving problems and developing The competencies needed to be economically self-sufficient by carrying out practical applications of creativity, production and marketing of various artistic works, instead of being a burden on their families and societies, thus they can be spared many social problems such as violence, extremism and deviation, by venting emotions and their latent energies and directing them in a way. Ideally, therefore, the art education teacher has a great responsibility to help students develop the skills and provide the necessary expertise, and because of the importance of this, the current study came to identify the degree of practice of art education teachers in Jordan of teaching skills in light of the knowledge economy from the point of view of their supervisors.

\section{the study Problem:}

Despite the Jordanian Ministry of Education's adoption of the knowledge economy, and its serious interest in it through the development of art education curricula in the year 2004-2005 $\mathrm{AD}$, printing teachers' guides and student books, and providing a set of training programs for teachers, as the teacher is the main guide for teaching and learning processes In order to qualify in a way that ensures the implementation of the requirements of a knowledge-based economy, this does not necessarily mean that the current reality of art education has effectively changed, as we find that there are many art education teachers in schools still practicing traditional teaching methods that do not match the size of expectations. For his supposed role, which made him unable to face current challenges according to global developments, which must necessarily be reflected positively and effectively on learners, their behavior, your way of thinking, and their ability to research, experiment, innovate and use knowledge to solve problems.

\section{Procedural definitions:}

-Knowledge economy: It is to enable students to continuously keep pace with the developments of the age by developing skills in a manner that ensures the appropriate economic exploitation of wealth based on knowledge, its management and marketing.

-Supervisor of Art Education: is the person employed by the Ministry of Education, and he 
is mainly a teacher of Art Education, as he supervises teachers with the aim of improving the educational process by performing a job that includes following up, directing and evaluating art education teachers in schools

-Art Education teacher: He is one of the employees of the Ministry of Education, who carries out many tasks such as planning, implementation and evaluation in the educational process, in order to provide students with experiences and develop their skills to produce innovative artistic works, so that they can solve their problems and the problems of society.

Teaching skills: It is a set of behaviors that an art education teacher performs in order to deliver the necessary information and skills - in light of the knowledge-based economy vision - to students in the educational situation with the least effort and costs possible, and is represented in the current study, with the skills of planning, implementation, evaluation and use of technology.

\section{Theoretical framework:}

In the late twentieth century, national economies around the world witnessed unprecedented economic challenges and opportunities, and technological advances in electronics, the revolution in computer programs, and the expansion of communication infrastructure led to changing basic economic functions and interactions of marketing factors, which called on national and regional leaders to focus Increasingly, economic activities are based on knowledge.

The information and communication technology revolution has caused a tremendous shift in the economic, social and political relations in the world, as well as in the traditional concepts of place and time, by linking people to global events and variables in an instant, and this had benefits and benefits for humanity in many different aspects of life, the most important of which are scientific and educational, where Technology played a fundamental role in moving towards the knowledge economy, as it is based on the research and development system.

Thus, the knowledge economy for global organizations constituted an incentive to move towards scientific knowledge and technology that in turn helps to achieve better competitive advantages than others, by creating new technologies that generate new skills, experiences, services and goods, because the first factor for economic growth is innovation, acquisition and dissemination of current knowledge, And the innovation and dissemination of new knowledge, Education Reform for Knowledge Economy (ERFKE) is that economy that revolves around knowledge and its acquisition, sharing, use, employment, creation, and production, with the aim of improving the quality of life in its various fields by making use of information services Rich, advanced applications, as this is done through the use of the human mind as a knowledge 
capital, in addition to employing scientific research to bring about a set of strategic changes in the economic environment and organize it to become more responsive and in line with the current challenges of globalization, information and communication technology, the universality of knowledge, and sustainable development in its concept. The Integrative Holistic.

Given the importance of a knowledge economy and a cycle in sustainable development, the Ministry of Education has, since 2009, implemented an educational development project directed towards the knowledge economy, with the aim of enabling the educational system to graduate individuals who possess higher-order thinking skills and are qualified to employ them in solving problems and producing creative solutions, which may qualify them. To effectively contribute to dealing with the requirements of a global competitive knowledge economy.

The educational development plan towards a knowledge economy aims at a real investment of knowledge, as the developed curricula seek to make the student distinguished by the search for knowledge, generate new knowledge, and communicate with others in multiple ways committed to the ethics of teamwork that includes respect for others, good listening and objectivity in dialogue, and the practice of thinking Critical, creative, and scientific problem solving on an ongoing basis and uses that in decision-making, as well as using information and communication technology with perfection, safety and ethics in research, analysis, data processing, presentations, and other advanced levels, as well as recognizing itself at high levels and practicing self-evaluation processes on an ongoing basis.

The knowledge-based economy has been based in its development on the accumulation of knowledge increasingly over time, the linkages of knowledge have been utilized in the form of goods and services that have been produced and made available to meet social and economic needs, knowledge has been incorporated into the production function in the form of human capital, whereby organizations perform Socialism plays a pivotal role in economic development based on information, as educational institutions, governments, nongovernmental organizations and private sector institutions generate, store and disseminate knowledge, by providing the infrastructure for this, in addition to preserving the intellectual property rights of individuals and organizations.

The role of specialists in knowledge economy is to provide the skills, experiences, practices, strategies and departments necessary to acquire and develop a scientific culture. Their work is no longer confined to the world of libraries, as we find in countries with developing economies that seek to reduce dependence on knowledge generated by rich countries. The development and promotion of new professional descriptions with high experience in knowledge generation 
and knowledge management are essential to support these paradigm shifts.

Numerous technical and scientific studies have emphasized the importance of developing broad mental habits rather than focusing on specific skills for work. It is believed that these habits, such as critical thinking and effective communication, contribute to providing students with life skills that move between professional and personal fields. In the current economic context, they engage Workers in the new knowledge economy in solving new and emerging problems around the world, and the skill in using appropriate technology, and it seems that there are clear similarities between the broad habits of the mind historically linked to the arts and sciences, they contribute to raising the competencies that are necessary for professional success in the new economy and convergence Increased global knowledge, the competencies needed for career success, and the increase in the number of students who favor career-oriented specializations that call for an improved understanding of the overall relationship between disciplines, as well as the development of competencies related to the modern economy that should work to develop tangible job skills.

The information society depends mainly on the human mind, and the human capital dimension is the backbone of the knowledge economy and the main key to the success of comprehensive sustainable development. Societies still strive to achieve growth and development in order to obtain desirable levels of economic and social development.

The importance of human capital theory is not limited to the current policy debate on skills improvement issues but to the broader relationship between undermining documents, jobs, rewards, and investment in education that is based on a political equation of high skills equal to high wages. User models for financing higher education are based on the opinion of the top Human money, according to which the palm tree reflects the level of skill, so that workers receive the light of low skills at low wages because the market value of labor is limited because other people are able to do the same work, and on the other hand, it is assumed that the workers with high skills will be absorbed more because they are more productive and developed. They have a greater market value.

The knowledge economy requires the development of the local community by achieving high levels of knowledge, competence, technological and computer skills, and this requires changing the role of the teacher and teaching and developing methods of teaching methods, classroom environment, equipment, curricula, books and others.

Curricula in the era of the knowledge economy have become a major responsibility on the shoulders of teachers, to be more creative and diversified in their dedication, to help their students reach the required educational outcomes, by facilitating the learning process inside 
and outside the classroom by providing techniques and educational aids and using information technology tools. And communications, and the use of the Internet to obtain knowledge, so that it enriches the curriculum, the student, and the teacher alike, in order to diversify the sources of access to information and deepen it, and to provide strategies for developing thinking, investigation and searching for solutions facing it, by participating with students to produce knowledge, And coping with the challenges and requirements of the knowledge economy by producing new and effective knowledge for the development of the local community.

Thus, we find that the teacher has a fundamental and pivotal role in changing the vision of the Ministry of Education based on the knowledge economy, through the resurrection of many practices that will enrich the educational process, such as good planning, effective implementation and realistic evaluation, and providing the necessary experiences that students need in their practical life. Through developing their various skills, self-development, providing them with realistic experiences, training in creative thinking skills, discipline, respect for others and independence, and motivating them to search for knowledge, employ new knowledge, use information technology, raise their professional and personal competence, solve problems, creative solutions, economize materials and employ them appropriately, in order to prepare them for the subsequent stages And their integration into the labor market to be active citizens in society, and able to better meet its needs.

\section{Discussing the results:}

The results of the current study were dealt with and discussed according to the study questions as follows:

\section{First: Results related to the first question:}

As for the degree to which art education teachers practice teaching skills in light of the knowledge economy from the point of view of their supervisors? To answer this question; The arithmetic averages and standard deviations were calculated for the estimates of the study sample individuals on each scale of the technical education teachers 'practice of teaching skills in light of the knowledge economy from the point of view of their supervisors.

It turns out that the degree of art education teachers 'practice of teaching skills in light of the knowledge economy from the point of view of their supervisors is (high), with an arithmetic mean (2009) and a standard deviation (0.20). The concept of knowledge economy was high, as the first field (planning) came first with an arithmetic average (401) and a high degree), and this may be attributed to the importance of planning the educational process, which facilitates the task of the art education teacher in the teaching process, whether it is for the teacher or the learner. The result with the study of Al-Smadi (2012), which was high on the field of planning, 
followed in second place by the second field (taqiyya) with an arithmetic mean (2) and with a high degree), while the third field (evaluation) came in third place with an arithmetic average (345) and with a high degree This result differs with the study of Zaza, Hila, and Al-Qudah, in which the degree of teachers 'practice of teaching and evaluation strategies came to a moderate degree. The fourth field (the use of technology) came in last place with an arithmetic average (2009) and a medium degree), and this may be due to the modest nature of the capabilities in It is related to the availability of computers in some schools, and this result is consistent with the results of the study of Al-Tuwaisi (2012), where the skill of using technology came in the last visual, as well as with the study of Illimat (2012) where the practice of teachers in the skill of using technology came to a moderate degree, as also noted from the table No. (2) The existence of one field (the use of technology) that came with the degree of practice

Medium), and (7) fields that came with a (high) degree of practice, which are respectively (planning, implementation, evaluation), where all of them were of a high degree, and this result is consistent with the study of Illimat (2012), which showed that practicing all skills was of a high degree.

It is also evident from Table No. (2) that the degree to which art education teachers practice teaching skills in light of the knowledge economy from the point of view of their supervisors is (high) with an arithmetic mean (205) and a standard deviation (1020), where the paragraph is hungry; The period of time allocated for observing the lesson is committed in the first place with an arithmetic average (4.2) and with a high degree attractive), followed in the second place by the paragraph: It takes into account the material and social capabilities of the school environment with an arithmetic average (441) and a very high degree), while the paragraph motivates students to The exchange between them of actions through electronic communication channels in the last rank with an arithmetic average (151) and a degree of (solid), and it is noticed from Table No. (3) the presence of (6) paragraphs that came with a very high degree), and (2) a paragraph with a high degree), and (10) paragraphs of medium degree, and (5) paragraphs of degree (strong.(

As for the first area: planning: the degree of art education teachers 'practice of it was (high) with an arithmetic mean (401) and a standard deviation (5.85), and it came first, where the paragraph: takes into account the material and social capabilities of the school environment in the first place with an average My account is (441) and with a very high degree) and this indicates the extent to which art education teachers take into account the nature of the possibilities available in schools and the material capabilities of students, followed by the 
second place, the paragraph; He is committed to the daily planning of lessons continuously, with an average of (418) and a degree of (high), and this may be attributed to the follow-up of the school principal and the educational supervisor of art education teachers, while the paragraph is hungry: Chooses selected topics on national and social events in the last place with an average of ( 3 ، 45) (And to a high degree), and this may be attributed to the commitment of art education teachers to the Artistic Education Curriculum, as the coverage of these topics is available instead of the Art Education teacher

As for the second field: Tweeting: the degree of art education teachers 'practice of it was (high) with an arithmetic mean (209) and a standard deviation (1090), and it came in second place, where the paragraph came: The period of time allocated to the implementation of the lesson is committed in the first place with an arithmetic average ( 486 (and with a very high degree), followed in the second place by the paragraph: "A process is carried out in front of the students with some skills related to the lesson with an arithmetic average (4) and a high degree Jeddah), and this may be attributed to the need for practical demonstration in the art education subject to provide students with the necessary realistic skills While the period came; students are given sufficient time to complete the tasks and practical tasks required in the last place with an average (2000) and a (low) degree, and this may be attributed to insufficient time allocated to art education classes, trade in artistic works represented by one class per week

As for the third field: evaluation: the degree of art education teachers 'practice of it was (high) with an arithmetic mean (345) and a standard deviation (2008), and came in third place, where the paragraph came: Encourages students to evaluate their own performance in the first place with an arithmetic average ( 42 (and with a very high degree), and this may be attributed to the importance of self-evaluation in art education, followed in second place by the paragraph: students perform, through continuous observation, an arithmetic average (4.00) with a high degree), and this may be attributed to the lack of sufficient time For evaluation in art education classes due to the need to cover subjects during the semester, while the paragraph came: the next steps are planned based on the answers of students in last place with an arithmetic average (205) and a degree (medium), and this may be due to the commitment of the art education teacher to the assigned curriculum.

As for the fourth field: the use of technology: the degree of art education teachers 'practice of it was average (with an arithmetic mean (2009) and a standard deviation (109), and it came fourth and last, where the paragraph came:“" The painting is assigned to refer to the global network of information and write reports that Related to the topics they studied, in the first place with an arithmetic average (440) and a very high degree), and this may be attributed to 
the importance of using technology in education, followed in second place by the paragraph "Focuses on the aesthetics and functionality of the works delivered through computer programs." With an arithmetic average (4) rru) and with a very high degree), and this may be attributed to the importance of encouraging students to implement artistic and aesthetic works through computer programs, while the paragraph came: "The students are motivated to exchange work among themselves through electronic communication channels in the last rank with an average of my calculation (121) and to a (low) degree, and this may be attributed to the teacher's modest experience in the field of exchanging information through social media channels due to its relatively newness.

Second: The results of the second question: "Does the degree of artistic education teachers' practice of teaching skills differ in light of the knowledge economy from the point of view of their supervisors according to the difference of two variables: gender and number of years of experience,"?

To answer this question; The arithmetic means and standard deviations of the estimates of the study sample individuals were calculated on the paragraphs of the scale of artistic education teachers 'practice of teaching skills in light of the knowledge economy from the viewpoint of their supervisors combined, according to two variables: gender and number of years of experience.

It is noticed that there are apparent differences between the arithmetic averages of the estimates of the individuals of the study sample on the paragraphs of the scale of artistic education teachers 'practice of teaching skills in light of the knowledge economy from the viewpoint of their supervisors depending on the two variables: gender and number of years of experience, and to determine the statistical significance of these differences, a two-way analysis was applied. ANOVA) Non-reactive.

\section{Recommendations:}

1- Encouraging art education teachers to use information and communication technology and employ it effectively, by holding training courses and workshops .

2- Designing training programs for art education teachers that include the skills that the study results revealed, and for which the degree of their practice was low.

3- Conducting more studies on knowledge economy skills in teaching from other aspects.

\section{References:}

1- Abu Bider, Muhammad. (2007). The role of the knowledge economy in developing the interest-based system in Jordan. Unpublished Master's thesis, Yarmouk University.

2- Al-Khaza'leh, Wasfi and Al-Zaboon, Mansour and Dhiabat, Muhammad and Issa, Ahmed. 
(2013). Evaluating the effectiveness of the physical education quota aspects in light of the educational development standards towards a knowledge economy in the schools of the governorate of Irbid. Manara, 19 (3), 143-172.

3- Al-Da'ami, Hoda and Al-Athari, Adnan. (2010). The knowledge economy and its implications for human development. Jarir Publishing and Distribution House: Amman.

4- Al-Rubaie, Zahir, Al-Azem, Wasfi and Al-Shaboul, and Qasim. (2006). Teacher's Guide / Art Education / Grade 8. The Ministry of Education: Administration of curricula and textbooks. 5- Al-Rifai, Munther. (2008). Technical education curricula developed according to the vision of the knowledge economy in Jordan. Unpublished Master's thesis, Yarmouk University.

6- Ramadan, Essam. (2015). The degree of availability of knowledge-based economics skills among students of the Faculty of Social Sciences at Imam Muhammad bin Saud Islamic University from the point of view of faculty members and students. The Jordanian Journal of Educational Sciences, 11 (2), 219-237.

7- Al-Zeyoudi, Majid. (2012). The Role of Information and Communication Technology for the Education Development Project towards a Knowledge Economy in Developing the Life Skills of Government School Students in Jordan, The Arab Journal for the Development of Excellence, (5), 83-107.

8- Al-Saud, Khaled and Al-Amoush, Musa and Kamel, Faten. (2006). Teacher's Guide / Art Education / First Class. The Ministry of Education: Administration of curricula and textbooks. 9- Al-Shammari, Hashem and Al-Laithi, Nadia. (2008). Knowledge Economy. Safaa House for Publishing and Distribution: Amman.

10- Al-Tuwaisi, Ahmad. (2014). The degree to which teachers of professional education practice the competencies of the knowledge economy from the viewpoint of educational supervisors in Jordan. The Jordanian Journal of Educational Sciences, 10 (1), 37-54.

11- Smadi, Hisham. (2012). The degree of application of the principles of knowledge economy at Princess Noura Bint Abdul Rahman University from the point of view of the faculty members. The Saudi Journal of Higher Education, (7), 125-141.

12- Zaza, Haydar and Hilat, Mustafa and the Judges, Muhammad. (2012). The degree of knowledge of MoE teachers in Jordan of teaching and evaluation strategies according to the knowledge economy and the degree of their practice of it from their point of view. King Saud University Journal, 24 (3), 619-652.

13- Abdul Haq, Zahrieh and Soman, Ahmad. (2014). The degree of consistency of the Arabic language study for the fourth grade of the basic course of the modern educational trends included in the Education Development Project (ERFKE). Education and Psychology Letter, 
147 (4), 135-155.

14- Abdel Hamid, Hussein and the Judges, Khaled and Abu Labda, Khattab. (2007). A comprehensive national assessment of knowledge economy skills, First Report: The National Center for Human Resources Development (NCHRD) publications series (921), Jordan.

15- Illimat, Muhammad. (2013). A degree that represents elementary school teachers in Jordan for knowledge economy skills and their relationship to their teaching practices from the point of view of their supervisors. Al-Manara Magazine, 9 (3), 383-411.

16- Alqarala, Basil. (2009). The components of the knowledge economy included in the books of Islamic education for the primary and secondary stages, an "analytical family". Unpublished $\mathrm{PhD}$ thesis, University of Jordan.

17- Ahmed. (2013). The skills of cognitive economics mentioned in the chemistry textbook for the second year of secondary school and the degree to which teachers have them. Journal of Human and Social Sciences, (13), 1--22.

Al-Qaisi, Muhammad. (2011). Features of the knowledge economy included in the content of forensic science courses in the secondary education development project in the Kingdom of Saudi Arabia. Unpublished Master's thesis, Mutah University.

19- Mustafa, Muhannad and Kilani, Ahmad. (2011). The degree to which Islamic education teachers practice teacher roles in light of the knowledge economy from the point of view of their supervisors in Jordan. Damascus University Journal, 27 (3 + 4), 681-718.

20- Trustworthy, Mona. (2003). Towards a new vision for educational research in the field of knowledge economy. Ministry of Education, Amman, Jordan.

21- Al-Hashemi, Abdul-Rahman and Al-Azzawi, Faiza Muhammad (2009). Knowledge economy and teacher training. University Book House: Al-Ain.

22- Al-Hashemi, Abdul-Rahman and Al-Azzawi, winner. (2007). Curriculum and knowledge economy. Al-Masirah House for Publishing, Distribution and Printing: Amman.

23- Al-Waeli, Nadia. (2012). Effective economics is an analytical study of the post-knowledge economy. Safaa House for Printing, Publishing and Distribution: Amman.

24- Bonal, X. \& Rambla, X. (2003). Captured by the Totally Pedagogized Society: Teacher and Teaching in the Knowledge Economy. Globalization, Societies and Education, 11 (2), 169184.

25- Brown, P. \& Lauder, H. \& Ashton, D. (2007). Education, Globalisation and the Future of the Knowledge Economy. European Educational Research Journal, 7 (2), 131 - 156.

26- Cader, H. (2008). The Evolution of the Knowledge Economy. The Regional Analasis \& Policy. 38 (2), 117- 129. 
27- Seifert, T. (2008). Is Majoring in the Traditional Arts and Sciences Preparing Students for the New Economy. National Opinion Research Center, 8 (2) online, from; http://www.liberalarts.wabash.edu/lao-8-2-arts-sciences-economy

28- Tarango, J. \& Mastromatteo, J. (2017). The Role of Information Professionals in the Knowledge Economy. Chandos Publishing: Mexico.

29- Yim-Teo, T. (2004). Reforming Curriculum for a Knowledge Economy: the Case of Technical Education in Singapore. Paper presented to the NCIIA 8th Annual Meeting Titled: Education that Works: Annual Conference; Hadley 137-144.

30- Tasnim Yahya AL-SAYED, Zainab Abdel Hafiz FARGHALY, Osama Muhammad HUSSEIN, Khaled Mostafa MOHAMED, THE EFFECTIVENESS OF A KNOWLEDGE TRIP IN DEVELOPING PLANNING SKILLS FOR STUDENTS OF THE CLOTHING AND TEXTILE DEPARTMENT, International Journal of Education and Learning Research, Vol. 2, No. 2, 2019, pp. 8-15.

Received: February 10, 2020

Accepted: April 30, 2020 